\title{
Las relaciones comerciales de granos y alimentos en la frontera México-Estados Unidos: sus desafíos y oportunidades
}

\author{
Jaime Mariscal O. \\ Área de Desarrollo Rural \\ CEESTEM
}

\section{Resumen}

El objeto de este trabajo es hacer un breve análisis de un proceso que bien puede desembocar en la pérdida de la relativa autonomía nacional, el de la creciente dependencia alimentaria, que pone en peligro la seguridad alimentaria de la población mexicana. El otro problema a analizar se refiere al papel que juega el comercio de alimentos en la zona fronteriza que, con la devaluación del peso mexicano, ha provocado cambios bruscos en la oferta y demanda de dichos productos. Con base en lo anterior, se puede afirmar que la política económica del Estado mexicano, favorable al desarrollo agrícola del Norte, y que en última instancia responde al requerimiento del mercado norteamericano, beneficia a un grupo reducido de empresarios agrícolas coludidos con las transnacionales estadounidenses, generando contradicciones de gran envergadura en la economía nacional. Finalmente, se plantea como estudios necesarios analizar las limitaciones o posibilidades de la estructura productiva nacional.

Palabras clave: dependencia alimentaria, medidas proteccionistas, producción agrícola, comercio de granos, exportaciones, importaciones.

\begin{abstract}
The objective of this document is to offer a brief analysis of a process that may result on losing the relative national autonomy. It means the increasing food dependency that jeopardizes the food surety for Mexican people. The other problem refers to the role that the food industry plays - which in front of the peso devaluation - has been the cause of sudden changes on offer and demand of these products. Based on the before mentioned, it can be affirmed that the economical politics of the Mexican States, which has favored the Northern agriculture development to meet the requirements of the American market, only benefits a small group of agriculture businessmen partnered to American worldwide companies. This partnership is creating critical contradictions to the domestic economy. Finally, it brings out that it is necessary to study and analyze the limitations and possibilities of the domestic productive structures.
\end{abstract}

Keywords: food dependency, protectionist measures, agriculture production, seeds trade, exporting, importing. 


\title{
LAS RELACIONES COMERCIALES DE GRANOS Y ALIMENTOS EN LA FRONTERA MEXICO-ESTADOS UNIDOS: SUS DESAFIOS Y OPORTUNIDADES*
}

\author{
Por \\ Ing. Jaime Mariscal $\mathrm{O}$ \\ Coordinador del proyecto de Alimentos, \\ Area de Desarrollo Rural, \\ CEESTEM.
}

\section{INTRODUCCION}

Las modalidades que caracterizan a la compleja red de interrelaciones económicas, políticas y socioculturales entre México y Estados Unidos, constituyen uno de los ejemplos más nítidos del papel que juegan los países del Tercer Mundo en la división internacional del trabajo y en el proceso de internacionalización de capital, hasta hoy consolidado.

Los esfuerzos de México por reducir su dependencia a través de la industrialización, limitada entre otras causas por la falta de capitales, llevó a alentar la inversión extranjera, orientando ésta a la industria manufacturera. No obstante, si bien México ha logrado reducir relativamente sus importaciones de manufacturas, no ha sucedido así con los bienes de capital y tecnología. De este modo,el llamado "milagro mexicano" se ha acompañado de entradas masivas de capital extranjero, principalmente norteamericano, así como de un continuo proceso de importaciones de bienes de capital, tecnología y ciertas materias primas.

En el marco del intercambio comercial, y pese a los esfuerzos de México por diversificar sus mercados, los Estados Unidos representan su principal socio comercial. Estados Unidos es y seguirá siendo para México la fuente básica de tecnología y bienes de capital, y hoy como nunca también de alimentos, principalmente granos.

Las exportaciones de México a Estados Unidos pasaron de un promedio anual de 1,813 millones de dólares entre 1974-76 a 6,629 millones anuales en el período 1977-81. A este incremento de las exportaciones le correspondieron considerables incrementos en sus importaciones procedentes del vecino país, las cuales pasaron de un promedio anual de 3,887 millones de dólares en el primer período, a 8,653 millones en el segundo.

Sin lugar a dudas, estos datos reflejan un constante déficit en la balanza comercial de México con los Estados Unidos, el cual se aproxima a los

*Colaboración de Marf́a del Carmen García A. 
2,000 millones de dólares anuales entre 1974-81. El problema comercial se agrava si tomamos en cuenta que más del $65 \%$ de las exportaciones e importaciones se realizan con Estados Unidos y por lo tanto, más del $60 \%$ de nuestro déficit comercial es precisamente con este país. El comercio exterior entre amb̀os países refleja asimismo las diferencias abismales de las estructuras productivas: del total de las exportaciones mexicanas, el $40 \%$ o lo constituyen bienes de consumo y el $60 \%$ bienes de producción, principalmente petróleo y sus derivados; contrariamente, del total de las exportaciones norteamericanas a México, el 8.7 \% son bienes de consumo y más del 90 \% corresponde a bienes de producción. 1

Pese a esta relación desigual, que rebasa el marco meramente econóEsta situación, aunada a una de las peores crisis por la que atraviesa el capitalismo mundial que afecta severamente a la economía norteamericana y consecuentemente a México, plantea la urgente necesidad de reducir nuestra excesiva dependencia comercial y financiera con los Estados Unidos.

Si en la década de los sesenta la política norteamericana hacia México con medidas como el dumping del algodón, la Operación Intercepción y las restricciones a las exportaciones agropecuarias, afectó gravemente a la economía de nuestro país, las recientes medidas como la reducción de la cuota migratoria, las presiones del gobierno norteamericano para que México ingrese al GAAT, las medidas proteccionistas a nuestras exportaciones y el querer culpar a México por el problema del desempleo en Estados Unidos, constituyen factores que agravan aún más el deterioro de la economía nacional.

No es objeto de esta ponencia analizar las complejas relaciones MexicoEstados Unidos, sino más bien hacer un breve análisis de un proceso que bien puede desembocar en la pérdida de la relativa autonomía nacional: nos referimos a la creciente dependencia alimentaria, que pone en peligro la seguridad alimentaria de la población mexicana. El otro problema a analizar se refiere al papel que juega el comercio de alimentos en la zona fronteriza que, con la devaluación del peso mexicano, ha provocado cambios bruscos en la oferta y demanda de dichos productos.

\section{ESTRUCTURA PRODUCTIVA AGRICOLA MEXICO-ESTADOS UNIDOS}

Los impresionantes avances que en materia de ciencia y tecnología agrícola han desarrollado los Estados Unidos a partir de la posguerra, lo

1“'Intercambio comercial México. Estados Unidos", en : El comercio exterior de México, Ed. Siglo XXI. México. 1982 . 
han convertido en el líder hegemónico del comercio agrícola mundial y en uno de los principales productos de insumos tecnológicos en la materia. ${ }^{2}$

La modernización agrícola norteamericana lleva a la búsqueda de ganancias y en este sentido a la necesidad de expandir nuevos mercados más allá de su territorio. Por un lado, se hacía necesaria la expansión de las exportaciones agrícolas, y por otro, la expansión de las industrias productoras de maquinaria agrícola, fertilizantes, pesticidas, herbicidas, semillas mejoradas, material genético y todo tipo de innovaciones tecnológicas y científicas en materia agropecuaria. Así también, la consolidación de la industria procesadora de alimentos requería expandir su campo de operación. ¿Como lograr éstos objetivos de tal manera que no entren en contradicción con sus propios sectores productivos?

La hábil política del gobierno estadounidense, basada en el dominio económico y tecnológico, se orientó a establecer mecanismos acordes con su visión expansionista: desalentando la producción de cereales, de la que ya era líder, condicionando su ayuda externa y otorgando facilidades crediticias para su adquisición; impulsando la producción de productos y materias primas que no compitan con su mercado y que sean favorables a sus industrias de insumos y procesadoras de alimentos y fomentando la producción agrícola en productos en los que no posee ventajas comparativas $y$ que sean necesarias a su demanda interna. ${ }^{3}$

Así, el trasplante de la modernización agrícola a países en desarrollo adquiere modalidades que difieren de la norteamericana. En México la llamada "revolución verde" impulsada en su inicio por la "filantrópica" Fundación Rockfeller se hizo de manera selectiva ya que la estructura agraria y su contorno económico social no permitían la generalización del modelo, el cual destruye a pequeños productores y fortalece a grandeš productores que además de que poseen grandes extensiones de superficie agrícola, cuentan con la capacidad de responder al uso masivo de insumos y tecnología.

La estrecha vinculación que se establece entre funcionarios mexicanos y estadounidenses involucrados en materia de desarrollo agrícola contribuyó

\footnotetext{
2 Los Estados Unidos cuentan con una superficie de tierras cultivables de $\mathbf{4 3 0}$ millones de hectáreas, de las cuales se utilizan para el cultivo alrededor de 200 millones, debido al exceso de su capacidad productiva. Posee una elevada mecanizacion agrícola, utilizando en la actualidad cerca de 5 millones de tractores, casi un millón de cosechadoras y millones de aparatos mecánicos para usos variados. El uso generalizado de fertilizantes, mejoramiento de las técnicas del cultivo y la incorporación de los avances en materia de riego,le permiten la obtención de una elevada productividad y el poco empleo de fuerza de trabajo. Estos factores han hecho que el $20 \%$ de las exportaciones mundiales procedan de este pais, y que mantenga su liderazgo en materia de cereales. Respecto a la ganaderfa bovina, ocupa el $12.3 \%$ de las existencias mundiales; es decir, 116 millones 375 mil cabezas. En cuanto a producción de carne absorbe el $22 \%$ de la produccion mundial. ("Intercambio comercial México-Estados Unidos", en: El comercio exterior de México. Ed. Siglo XXI, México, 1982).

$3 \mathrm{La}$ politica de la Commodity Credit Corporation dice mucho al respecto.
} 
definitivamente al trasplante en México de la revolución verde. 4 Y aquí se hace evidente la miopía al no tomar en cuenta las diferencias estructurales del agro mexicano frente al del vecino país: en Estados Unidos la mecanización se vincula al objetivo de reducir el empleo de fuerza de trabajo en el campo; en cambio en México, el exceso de mano de obra disponible y la incapacidad de la industria para absorberla hacen que la mecanización tenga un impacto negativo.

En este contexto, la revolución verde en México se orienta al fortalecimiento de la agricultura comercial, principalmente la destinada a la exportación y la nueva industria procesadora de alimentos que además de generar cambios en los patrones de cultivo implicaba un cambio drástico en los patrones de consumo de la población.

En México el impulso dado a las políticas de las "ventajas comparativas" llevó a fortalecer la agricultura de exportación. Por otro lado, en pro de la industrialización "nacional" se alentó la inversión extranjera directa que no tardó en acudir al llamado, estableciéndose en el sector manufacturero predominando la rama de procesamiento de alimentos.

A partir de los años cuarenta,la política del Estado mexicano en materia de desarrollo agrícola se caracteriza por la búsqueda de recursos externos para financiar la creación de una gigantesca red de infraestructura económica y de servicios orientada en lo fundamental al desarrollo de la agricultura comercial del noroeste y noreste del país, dejando al margen de estos beneficios a las regiones del centro y fundamentalmente el sur del país, las cuales se caracterizan por estructuras agrarias campesinas orientadas a la producción de maíz y frijol, alimentos fundamentales del mexicano.

A la par de este proceso, el capital extranjero, principalmente norteamericano, hacía lo suyo estableciendo filiales productoras de maquinaria agrícola e insumos, elementos necesarios del modelo de revolución verde, estableciendo industrias de alimentos procesados. La industria avícola lidereada por Anderson Clayton y Purina llevó al impulso de la producción de materias primas agrícolas para una nueva industria, también transnacional: la de alimentos balanceados para animales, dándose así el desplazamiento del cultivo del maíz por el cultivo del sorgo. Ejemplos como éste abundan, en todo caso se reducen a dos hechos de graves consecuencias para nuestro país: el descuido de la producción de alimentos tradicionales básicos y la necesidad de importación de nuevas materias primas agrícolas que debido al auge de industrias alimentarias, como la avícola, hacen insuficiente la oferta nacional de nuevas materias primas.

\footnotetext{
${ }^{4} \mathrm{~A}$ este respecto hay que observar la colaburación que prestó el Gobierno mexicano al programa conjunto con la Fundación Rockefeller a través de la Oficina de Estudios Especiales creado en 1943 a instancias de la Secretaría de Agricultura, y transformada en el Instituto Nacional de Investigaciones Agricolas.
} 
Por otra parte, México ha sido tradicional exportador de ganado en pie al mercado norteamericano. En este sentido, la política del Estado mexicano ha contribuido a crear las condiciones necesarias para la especialización de la zona norte de México en la producción de ganado para la exportación hacia los Estados Unidos, en vistas a la obtención de divisas. Esta especialización no ha sido del todo positiva pues queda sujeta exclusivamente a la dinámica del mercado norteamericano; su vulnerabilidad reside en que esta zona del territorio mexicano no es la única que produce ganado con las características de edad y peso que requiere el mercado del vecino país, pues también Canadá se incluye en las características de este comercio, lo que provoca la manipulación de los precios aunado a la falta de mercados alternativos para este ganado. Por otra parte, la explotación de becerros traslada gran parte del valor agregado a la economía norteamericana, valor que podría generarse a partir de la industrialización del ganado. Esta situación provoca hechos contradictorios pues México se ha convertido en importador de subproductos de la ganadería tales como pieles, vísceras, sebos, etc. Además, la ganadería mexicana y en particular, la del Norte, requiere de la importación de un paquete de insumos en donde se incluye material genético, productos veterinarios, semillas para pastos mejorados, etc., todo lo cual procede de los Estados Unidos. En lo interno, la exportación de ganado en pie beneficia a un reducido grupo de productores.

Aunque también es cierto, por otra parte, que el crecimiento de la población ha generado un aumento en la demanda de este producto; a pesar de ello, la ganadería norteña sigue orientándose a la exportación y la demanda nacional ha provocado la expansión de la ganadería hacia las áreas tropicales mediante sistemas extensivos de producción, generando graves desequilibrios ecológicos al convertir grandes extensiones selváticas en áreas de pastizales, así como también agudos conflictos sociales relativos a la tenencia de la tierra. ${ }^{5}$

En términos generales podemos afirmar que la política norteamericana y su ideología liberal, reflejada en los vínculos de la burguesía nacional con la norteamericana, ha sido determinante en el modelo de desarrollo agropecuario seguido a partir de los años cuarenta por nuestro país. Hoy más que nunca afloran las consecuencias económicas y sociopolíticas del transplante de un modelo de desarrollo basado en la obtención de altas tasas de ganancia. Veamos:

1) La estructura agraria se caracteriza por un continuo proceso de polarización social. En el noroeste y noreste del país existen emporios agrícolas vinculados al capital financiero y comercial transnacional; en el

${ }^{5} \mathrm{La}$ expansión de la ganaderfa en el trópico mexicano se ha visto reforzada a través del otorgamiento de crédito por parte de instituciones como el FIRA, que recibe financiamiento de organismos internacionales. 
sur y en menor medida en el centro del país, proliferan las explotaciones minifundistas, las cuales son incapaces de ofrecer un empleo permanente á los campesinos y de ahí la necesidad de desplazarse a otros lugares en busca de empleo temporal.

2) En el marco de la producción, México ha perdido la autosuficiencia en alimentos, principalmente cereales, y con ello la seguridad alimentaria de su población. La dependencia a través de la necesidad de importaciones resta parte de su autonomía como país. El valor de las importaciones de maíz y trigo pasó de 286 millones de dólares en 1974 a 752 millones en 1981; las importaciones de semillas y frutos oleaginosos pasaron de 137 millones de dólares a 505 millones en el mismo período; las importaciones de leche pasaron de 91 millones a 225 millones de dólares. En lo fundamental, estas importaciones provienen de Estados Unidos.

3) En lo que se refiere a las exportaciones agrícolas que siempre habían reflejado un saldo positivo respecto a las importaciones, hoy se presenta un proceso inverso. Además, el café, el jitomate, el algodón, las hortalizas y el ganado representan en lo fundamental los centros de gravitación de la exportación agropecuaria. Seis productos representaron en 1975 el $71.2 \%$ del valor de las exportaciones agropecuarias; estos mismos participaron con el 90 \% del valor de las exportaciones en $1981^{7}$. Estos productos en conjunto se vinculan al mercado norteamericano y "por las leyes económicas del proceso, a las empresas transnacionales" "8. La debilidad del país por ejercer un control en sus exportaciones, debido al dominio del mercado norteamericano, hace incierta esta actividad.

4) La creciente participación de Estados Unidos en la agricultura del país se da fundamentalmente en la producción de maquinaria e insumos para la producción y en la fase de procesamiento y comercialización. En 1965 del total de la industria de alimentos en México, cerca del $50 \%$ pertenecía al capital extranjero fundamentalmente norteamericano 9 . Otra fuente señala que las inversiones agroalimentarias de Estados Unidos en México pasaron de 107 millones de dólares en 1966 a 191 millones en 1974 y a 205 millones de dólares en 1977, representando, respectivamente, el 7.3 \% 5.2 \% y 8.5 \% de la inversión industrial de Estados Unidos en nuestro país. Se señala también que la tasa de beneficio de la inversión norteamericana en la industria agroalimentaria en México ha sido en los años señalados de 7.5, 16.8 y $9.3 \% 10$.

6 Algodón sin cardar, cafe crudo en grano, tomate, frutas frescas, legumbres y hortalizas, y ganado bovino.

7 Banco de México

8 Juan Ma. Alponte, Uno más uno, 30 de azosto de 1980, México

9 José Ceceña, México en la órbita imperial: las empresas transnacionales. Ed. El Caballito, 1970, México, p. 64 .

10 "El desarrollo agroindustrial: problemas y perspectivas" en A.L. CODAl, SARH, No. 6, México, 1982. 


\section{EL COMERCIO AGROALIMENTARIO EN LA FRONTERA MEXICO-ESTADOS UNIDOS.}

El acelerado crecimiento de población que experimenta la frontera norte de México, fundamentalmente por la migración de grandes masas de trabajadores que ven en esta región la perspectiva de su supervivencia, ha provocado no sólo la aparición de nuevos cenntros urbanos, sino graves desequilibrios económicos y sociales ante la falta de empleo y la carencia de vivienda e infraestructura social 11. La incapacidad de la estructura productiva para absorber la fuerza de trabajo en los estados del norte del país explica que la función de cientos de miles de trabajadores mexicanos se reduzca a constituirse en reserva de trabajo de la industria y agricultura estadounidenses.

La incapacidad del gobierno mexicano para responder al reto que se le presenta en las zonas fronterizas, ha llevado a un proceso de dominación, no sólo en el marco económico sino en lo político e ideológico 12 . En efecto, los programas federales se han reducido; 1 ) al otorgamiento de estímulos fiscales a la industria fronteriza y a las maquiladoras norteamericanas, y 2) al otorgamiento de permisos de importación para equipo y artículos "gancho" 13 a centros comerciales, y a la agricultura en maquinaria y equipo 14 . Esto ha permitido que los sectores más dinámicos del aparato productivo de la franja fronteriza estén dominados directa e indirectamente por el capital norteamericano.

En el marco del intercambio comercial fronterizo, y ante la falta de competitividad de la industria mexicana, la hegemonía se da en la producción manufacturera norteamericana originando que los residentes fronterizos adquieran desde artículos de primera necesidad hasta artículos suntuarios de procedencia extranjera, dentro de la misma franja. Pero el comercio de productos americanos rebasa la franja fronteriza ya que "los gastos efectuados por los mexicanos en lado norteamericano no se limitan a las compras locales, pues los establecimientos al por mayor en estas ciudades abastecen a un mercado que se extiende al interior de México"15

\footnotetext{
$11^{\mathrm{L}} \mathrm{La}$ frontera norte de México, seis estados que agrupan a 36 municipios, se extiende por más de 3,326 kilómetros. La población suma 5 millones de habitantes; destacan Tijuana y Ciudad Juárez, que concentran más de un millón cada una (...); se estima en un millón el número de personas que ingresa anualmente a Estados Unidos. En Tijuana, la densidad urbana es de 389 personas por kilómetroo cuadrado, en Nuevo Laredo de 164, y en Ciudad Juárez, de 140. La media nacional es de 34". (Situación Económica de México, BANAMEX, Vol. LVIII, No. 684, noviem bre, 1982, pp. 560-568).

12 Analizando los "patrones de consumo", la "visión ideológica", las normas de conducta y rasgos culturales de los habitantes de la región norteña se observan la influencia y los vínculos con la sociedad norteamericana y una débil y desarticulada vinculación con la realidad nacional.

13 SPyP. Programa Nacional de Desarrollo Fronterizo, abril de 1982, México.

14 Op. cit. "Casi el $100 \%$ de la producción del Programa de Industrialización Fronterizo se exporta al mercado norteamericano y entre el 60 y $70 \%$ de los salarios de los trabajadores de las maquiladoras se gastan en Estados Unidos" (Peter Baird. México-Estados Unidos: relaciones económicas y lucha de clases. Ed. Era, México, 1982, p. 233).

15 Fernández A.R. La frontera México-Estados Unidos. Ed. Terranova, 1980, México, p. 138.
} 
El crecimiento acelerado del comercio agropecuario entre México y Estados Unidos hace de las ciudades fronterizas el centro de operaciones, movilizando las actividades comerciales y de transporte, así como otros servicios. Como señalamos anteriormente, la estructura comercial agropecuaria entre ambos países es desfavorable a México ya que este importa granos, semillas oleaginosas, productos lácteos, alimento para el ganado, carne, subproductos pecuarios, etc. y exporta café, melaza, tomate, cebolla, melones, fresas y otras frutas, legumbres y hortalizas, ganado vacuno y otros; es decir,productos que compiten con la producción de Canadá y Florida.

Si bien es cierto que los estados fronterizos del Norte reflejan las diferencias económicas y sociales entre un país desarrollado -Estados Unidosy un país dependiente -México-, también lo es que la región norte del país se diferencía notablemente en relación a las otras. En materia agrícola dichas diferencias son más profundas. En efecto, los estados fronterizos poseen una estructura agraria comercial orientada en la fundamental a la exportación, lo cual refleja el apoyo indiscriminado del gobierno mexicano a esta región, proporcionando crecientes recursos. Los valles del Noroeste mexicano representan verdaderos emporios agrícolas semejantes a la moderna agricultura norteamericana. "Campo tras campo de jitomates, pepinos y pimientos forman una cobija de cuadros cuyas costuras son interminables, kilómetros de canales de concreto, tractores Ford y John Deere aran la tierra, y aviones y fumigadores sobrevuelan los campos cubriéndolos con sustancias químicas fabricados por Niagara y Dow".16

Estos hechos permiten afirmar que la política económica del Estado mexicano, favorable al desarrollo agrícola del Norte, y que en última instancia responde al requerimiento del mercado norteamericano, beneficia a un grupo reducido de empresarios agrícolas coludidos con las transnacionales estadounidenses, generando contradicciones de gran envergadura en la economía nacional en su conjunto.

Inmerso en el contexto de una de las peores crisis del capitalismo mundial, el deterioro económico de México llevó la devaluación del peso y, como médida de autonomía, a la nacionalización de la banca. Estos acontecimientos provocaron cambios bruscos en la relación comercial de las zonas fronterizas, y las reacciones de empresarios mexicanos y norteamericanos fueron las de declarar la política de la nacionalización como una medida "comunista". Las opiniones, en todo caso, reflejan el estado de la correlación de fuerzas entre los intereses empresariales de México y Estados Unidos.

En materia de intercambio comercial fronterizo, ante la devaluación los residentes de la frontera se vieron imposibilitados de continuar consumien-

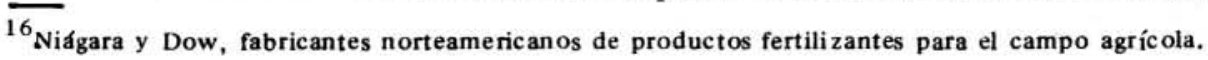


do bienes y servicios del 1ado norteamericano "y no sólo los residentes del lado mexicano concurrieron al mercado de bienes y servicios nacionales, sino que ciudadanos americanos procedentes de ciudades tales como San Antonio, Austin, y otras, acudieron al mercado nacional".1 7

Parecería ser que se le presentan a México condiciones propicias para fomentar sus exportaciones al vecino país. Así lo reconocen los gobernadores de los estados fronterizos de México y las agrupaciones empresariales, no sin antes solicitar al gobierno estadounidense poner fin al proteccionismo en contra de las exportaciones mexicanas. 18

Sin embargo, las medidas proteccionistas por parte de Estados Unidos van a continuar y lo demuestran los acontecimientos actuales; por otro lado, cabe preguntar si la capacidad de la estructura productiva de México tiene las bases para responder a este reto. Creemos que no. Además, la demanda del vecino país en la frontera mexicana se reduce a productos de bienes de consumo: aceites vegetales, arroz, café, azúcar, cereales procesados como tortillas, pan, pastas, galletas, harina de maíz y trigo; leche, manteca vegetal, productos infantiles, etc. Es decir, son productos en los que México es deficitario y de los cuales cubre la demanda interna a través de las importaciones que provienen en lo fundamental de Estados Unidos. Además, estos productos forman parte del programa de subsidio del Gobierno federal, por lo que, de incrementarse este tipo de comercio, el Gobierno mexicano estaría beneficiando o subsidiando el consumo alimentario de las poblaciones del lado de la frontera norteamericana. La protesta de los comerciantes fronterizos del país, hecha a CONASUPO para que cubra la demanda de estos productos, es incongruente con los intereses del país en su conjunto; los únicos beneficiarios serían pues, como de costumbre, los comerciantes.

Por otro lado, el comercio norteamericano se ha dedicado a recoger pesos mexicanos en las casas de cambio estadounidenses y con ello provee a las amas de casa norteamericanas para que vengan a "las poblaciones mexicanas a hacer sus compras de artículos subsidiados". 19

Finalmente, en lo que se refiere a otros productos manufacturados, en los que habría que analizar las posibilidades o limitaciones de la estructura productiva nacional, hay que señalar que: "el crecimiento inflacionario y la escasez de materias primas ha provocado incrementos en los precios de mercancías, por lo que las ventajas en los precios que representan los productos nacionales con respecto a los extranjeros se están reduciendo'”20

17 SPP op. cit

18 Excelsior, 21 de septiembre de 1982.

${ }^{19}$ Excélsior, 20 de septiembre de 1982.

20 SPP op. cit. 


\section{LAS RELACIONES COMERCIALES}

\section{BIBLIOGRAFIA}

BAIRD, Peter y McCaughan. México-Estados Unidos: relaciones económicas y lucha de clases. Ed. Era, México, 1982.

SCHMITT, M. Karl. México y Estados Unidos 1821-1973. Ed. Limusa, México, 1978.

FERNANDEZ, A. Raúl. La frontera México-Estados Unidos. Un estudio socioeconómico. Ed. Terra Nova, México, 1980.

BANCO DE MEXICO. Informes anuales, varios años.

INSTITUTO MEXICANO DE COMERCIO EXTERIOR. Comercio Exterior de México, Tomo III, Ed. Siglo XXI, México, 1982.

CECENA, José L. México en la órbita imperial: las empresas transnacionales. Ed. El Caballito, México, 1970.

ESTEVEZ, V. Jaime y B. Portilla. "El desarrollo agroindustrial ¿Agronegocio o nuevo orden económico internacional?", en: El desarrollo agroindustrial: problemas y perspectivas en América Latina. CODAI, SARH, México, 1982. (No. 6).

Uno más uno, 30 de agosto de 1980.

Excélsior, 30 de septiembre de 1982 .

Excelsior, 21 de septiembre de 1982.

BANAMEX. Examen de la situación económica de México, vol. LVII, No. 684, noviembre de 1982.

SPP. Programa nacional de desarrollo fronterizo, abril de 1982, México. 